\title{
Perception and Utilization of Health Care Services in Family Practice Centers- Suez Canal Area-Egypt
}

\author{
Sameh F. Ahmed, Mohammad A. Arafa, Ahmed G. Abd-Elrahman \\ *Family Medicine department community of Medicine, Suez Canal \\ University \\ Received: January 2016 Accepted: March 2016
}

\begin{abstract}
Background: Users' perception of the provided health services could influence their utilization and satisfaction. Aim: To assess the community awareness, perceptions and factors affecting service utilization of university-owned Family Practice Centers (FPCs). Materials and Methods: This cross sectional study was conducted over a period of three months (15 May 2015 to 15 July 2015) in 9 rural and urban areas served by university-owned FPCs. Data were obtained from 900 respondents using a 22 points structured, interviewer-administered questionnaire. Results: The majority of respondents were aware of the Family Practice Centers ( $90.3 \%$ rural and $88.0 \%$ urban) and most of them (89.1 rural and $84.5 \%$ urban) have utilized these centers. The satisfaction of utilizers reached $88.6 \%$ and $80.3 \%$ in urban and rural areas respectively. Treatment with courtesy and competency of the medical team have constituted the main reasons of utilizers' satisfaction whereas, inadequacy of clinical services determined the main reason of their dissatisfaction in urban areas (46.7 \%) compared to long waiting time $(25 \%)$ in rural areas. However, inadequacies of clinical services also emerged as the main reason behind hesitancy to access Family Practice Centers among those who never visited these centers $(59.3 \%$ and $51.2 \%$ in rural and urban areas respectively). Conclusion: The local community awareness, utilization and satisfaction with university Family Practice Centers were very high in both rural and urban areas. Treatments with courtesy and competency of the medical team have constituted the main reasons of utilizers' satisfaction while, inadequacy of clinical services determined the main reason for both dissatisfaction and non-utilization.

Key words: Patients' utilization, Family Practice Centers, community perception *Corresponding author, Sameh Fawzi < SamehFawzi3691@gmail.com>
\end{abstract}

\section{Introduction}

The Alma-Ata international conference defined Primary Health Care as "the essential health care made universally accessible to individuals and acceptable to them, through their full participation and at a cost the community and country can afford. ${ }^{(1)}$ The Government of Egypt was a signatory to Alma-Ata's declaration and committed to providing quality primary health care services to achieve health for all by the year 2000 .

The Egyptian health sector could be described as vertical, centralized, and fragmented. This limits Egypt's opportunities to take advantage of available practices in medicine and realizing potential gains for improvements in efficiency and equality. The country has failed like many others to achieve the health for all goals by the year 2000 and free public health care services are still limited in terms of accessibility, availability, and quality. ${ }^{(2)}$ Moreover, 72 percent of all healthcare costs are covered out of pocket despite that more than half of the Egyptians has 
access to some form of health insurance. ${ }^{(3)}$

In Egypt, Ministry of Health $(\mathrm{MOH})$ continues to shoulder the bulk of the responsibility for meeting the health care needs of the general population. By 2016, the MOH was operating a total of 4,506PHC facilities distributed all over the country. Many other partners including Health Insurance Organization , university hospitals and private sector also participate in health care provision network in Egypt. ${ }^{(4)}$

In 1990 Suez Canal University established 10 FPCs to work in collaboration with nearby primary health care centers owned by Ministry of Health $(\mathrm{MOH})$ and spread along Suez Canal Governorates (Port Said, Ismailia and Suez) and North Sinai. Unfortunately this initiative had been aborted early and the twins separated. In 2015 North Sinai FPC had been separated and the remaining 9 centers continue to provide their services and bring healthcare as close as possible to their population. Unsurprisingly, most founders of these centers have been relocated in different Gulf countries in early $90^{\text {th }}$ and the resulting shortcomings in the delivery of services provided by university FPCs led to regression in utilization of most of these centers compared with $\mathrm{MOH}$ centers. As well, more regression of utilization has been noticed after 1996, when the Egyptian government through the Ministry of Health and Population (MOHP) introduced a health reform program to overcome problems of public health care system including health outcomes, accessibility, efficiency, quality, clinical effectiveness and consumer satisfaction. ${ }^{(4)}$

Unfortunately, the quality of public sector health care services has been cited as a problem in most reviews of the Egyptian health care system. In effect, poor quality of services led to lack of confidence and underutilization $(65 \%$ of all primary contacts for treatment were with private providers), resulting in rapid turnover of physicians, which, in addition to lack of resources and low treatment standards, further reduced quality of service. $^{(5)}$

Health seeking behaviour or utilization of health services is not just a one off isolated event. It is part and parcel of a person's, a family's or a community's identity, which is a result of an evolving $\operatorname{mix}$ of social, personal, cultural, political, economic and experiential factors. (6,7) Information obtained from this study will help the university hospital which is responsible for service delivery at these Family Health Centers target their education and community messages to address the fundamental elements that act as barriers to utilization of health services. It will also help the service providers at the facility level to develop strategies and action plans that will encourage utilization of provided services and therefore, improving health outcome for every individual in nearby community.

\section{Materials and Methods}

Study design: A cross-sectional, descriptive study design was employed in which interviewer-administered structured questionnaires were used to assess community awareness, perceptions and utilization of services provided by university-owned FPCs.

\section{Study setting}

The study was conducted in 9 areas (3 urban and 6 rural) served by 9 FPCs owned by Suez Canal University, Egypt. These centers provide a package of preventive and curative primary health care services to more than 200,000 individuals. Most of these FPCs (5 centers) locate a few 
meters far from primary health care (PHC) centers owned by MOH. Both types of centers provide primary health care services to the same population but with more cost for university owned FPCs and wider range of services for $\mathrm{MOH}$ centers including health office services. All University FPCs and $\mathrm{MOH}$ centers work for only 8 hours daily for 6 days/ week except one rural university FPC which provides 24 hours services all week days.

\section{Sampling}

All respondents (defined as any male or female 18 years old or more) who have attended the nearby health office of the PHC centers of MOH during the study period (15 May 2015 to 15 July 2015) for reasons other than death certificates and agree to participate in the study have been included in the study.

\section{Data collection and outcome measures}

A structured anonymous Intervieweradministered questionnaire was used to obtain data from the respondents. The interviewers were trained at the University Family Practice Centers for three days before field work. The primary outcomes were assessing the community awareness, perceptions and identification of factors that might influence utilization of services provided by 9 university Family Practice Centers.

\section{Questionnaire:}

The questionnaire was developed by the research team according to the literature review. It was written in Arabic language and composed of 22 questions to assess demographic characteristics of the respondents as well as their awareness, perceptions and utilization of the university FPCs. Utilization was defined as any visit to the FPC during the preceding two years of the study. The respondents' general satisfaction was assessed by asking respondents a direct question whether satisfied or dissatisfied with services provided by the university FPC. Thereafter, the dissatisfied utilizers listed the reason (s) of their dissatisfaction. These reasons were categorized into technical quality, interpersonal manner, communication, financial aspects, accessibility and availability of services).

\section{Data analysis}

Data were imported into SSPS software. Analysis included frequency distributions of different types of services utilized and the results are presented by making use of bar charts and tables. Comparison of the demographic characteristics and satisfaction between urban and rural areas was done using $x^{2}$ test and statistical significance was set at $\mathrm{P}<0.05$.

\section{Pilot study}

A pilot study was conducted on a small group of people (ten) at each health office to test the questionnaire. By doing a pilot study the feasibility of the study was investigated so that potential problems were identified and resolved before commencing the study.

\section{Ethical considerations}

Approval to perform the study was obtained from the Research Ethics Committee, Family Medicine Department, Suez Canal University, Egypt. Participants were given information to enable them to make decisions to either participate in the study or not. The benefit of taking part in the study was explained to the participants (to improve the quality of health care services provided by university- owned FPCs). 


\section{Results}

Table (1) Socio demographic data of the studied groups $(n=900)$. The study included 900 respondents (600 in rural areas and 300 in urban areas) with mean age $33.0 \pm 11.6$ years in rural and $36.0 \pm 13.9$ years in urban areas. Most of the respondents were females $(82.5 \%$ and $57.7 \%$ in rural and urban areas respectively). Regarding marital status most of the respondents in both rural $(87.3 \%)$ and urban $(70.7 \%)$ were married. The educational level was more in urban areas $(75.3 \%$ reached secondary level or more) compared to rural respondents where only $46.5 \%$ of respondents have reached the secondary level or more. As regard to working status, more of urban respondents was working $(49.7 \%)$ compared with only $15 \%$ in rural areas. Table 2: Relation between respondents' satisfaction and sociodemographic characteristics $\quad(n=706)$. This table shows that rural respondents were statistically more significantly satisfied with the health services provided by university FPCs compared with urban respondents $(\mathrm{p}=0.003)$. As well, no employment had significant relation to respondents' satisfaction with the health services provided by FPC $(p=0.001)$. On the other hand gender, age, marital status, educational level and distance to FPCs did not significantly affect the satisfaction of either rural or urban respondents $(p>$ $0.05)$.

Figure 1: Respondents`awareness of university FPCs $(n=900)$. This figure shows that most of the respondents in the rural areas (542 persons or $90.3 \%$ ) and urban areas (264 persons or $88 \%$ ) were aware of the presence of the university FPC in their village/ district. Figure 2: Utilization of health services provided by the university FPCs among aware respondents $(n=806)$. This figure shows that most of the aware persons (706 out of 806 aware persons) representing $89.1 \%$ in rural areas (483 respondents) and $84.5 \%$ in urban areas (223 respondents) had utilized the university FPC in their residence area while the remaining 100 persons representing $10.9 \% \quad$ (59 persons) of the rural aware respondents and $15.5 \%$ (41 persons) of the urban aware respondents stated that they had never utilized any of the university FPCs.

Figure 3: Utilizers' frequency of utilization of health services provided by the university FPCs $(n=706)$. This figure shows that outpatient and laboratory services ranked first in utilization and represent $63.8 \%$ and $34.1 \%$ for outpatient service; $49.3 \%$ and $34.1 \%$ for laboratory services in rural and urban areas respectively while vaccination service was the least in rural areas (2.9\%) compared with well-baby care in urban areas (4.9\%).

Figure 4: Utilizers satisfaction with health services provided by the university FPCs $(n=706)$. This figure shows that the satisfaction with the provided health service by the university FPCs as reported by people who have utilized these services reached $88.6 \%$ (428 persons) and $80.3 \%$ (179 persons) in urban and rural areas respectively.

Fig 5: Reasons of satisfaction with FPCs as reported by utilizers. The figure ranked treatment with courtesy (57\% in rural and $42.4 \%$ in urban) and competency of the medical team (21.1\% in rural and $37.5 \%$ in urban) as the main reasons of satisfaction with FPCs as reported by utilizers.

Figure 6: Reasons of dissatisfaction with the university Family Practice Centers as reported by the dissatisfied utilizers $(n=99)$. The figure shows that non- availability of specialties beside family medicine and non-availability of 24 hours service ranked first two reasons reported by the dissatisfied utilizers in urban areas while, long 
waiting time and non-availability of services like ultrasound emerged as the main reasons among dissatisfied utilizers in rural areas.

Figure 7: Needed services in the university FPCs from the point of view of utilizers $(n=706)$. This figure shows that adding other specialties beside family medicine services was the main need of both rural and urban clients (33.9\% and 59.7\% respectively). Extending laboratory services was the second demand for urban people (25.6\%), while ultrasound service was the second demand for the rural people (26.6\%).

Figure 8: Reasons of non-utilization of health services provided by University FPC among aware but non-utilizers $(n=100)$. This figure shows that the most giving reason for non-utilization services offered by the university FPC by the aware respondents was unavailability of different specialties representing 59.3\% (rural) and 51.2\% (urban).

\section{Discussion}

Review of literature demonstrates that general practitioners (GPs) have been the basis of providing primary health care services in many developed as well as developing health care systems. ${ }^{(7)}$ In Egypt, the concept of family medicine is one of the most significant changes that have been introduced by Suez Canal University since more than 3 decades when its Faculty of Medicine established the first Family Medicine Department in the Middle East. But Egyptians who used to consult specialists at all levels of medical care continue to have a negative perception of family physicians as unqualified and unreliable. This deeply rooted negative perception may be justified by the nature of medical education in Egypt that overlooked general practice and focused on other specialties and also to delayed implementation of the Egyptian health sector reform program (EHSRP) which actually started to support the concept of family doctor by year $2004 .{ }^{(7)}$ Even after all these initiatives, under recognition of primary health care continues to influence family doctors' willingness to stay in Egypt and many of them relocated in Gulf countries where they found more recognition and supportive health systems.

Despite these facts, the present study revealed high levels of awareness and utilization of FPCs in both rural and urban areas. As well, most of respondents were satisfied with their experience in both urban and rural areas. This high rate of respondents' satisfaction might explain the high rate of their reutilization of FPCs in both rural and urban areas. Another study showed a similar high utilization rate of primary health care services in 12 months before the study. ${ }^{(13)}$ In contrast to these findings, Umunna ${ }^{(14)}$ found low utilization of primary health care services in Nigeria although users have an overall good impression of primary health care services.

In the present study, the educational level was more in urban areas $(75.3 \%$ reached secondary level or more) compared to rural respondents where only $46.5 \%$ of respondents have reached the secondary level or more. But, there was no significant relation between respondents' satisfaction and educational level. This may be due to the recent availability of information to all people through the modern social media with continuous narrowing of the knowledge gap between different educational levels. These results are in accordance with another study done by Gadallah et $\mathrm{al}^{(8)}$ in Egypt and revealed that the level of satisfaction with primary health care services is not affected by gender or educational level 
of participants. ${ }^{(8)}$ In contrast to these findings, the rates of utilization and satisfaction were affected by education level in a Jordanian study. ${ }^{(15)}$

On the other hand, non-working status had significant relation to respondents' satisfaction with the health services provided by FPC $(p=0.001)$. This is probably because non-working people would not have other options of health services with which to compare or to their limited financial resources to access and utilize more quality services. In contrast to these findings, Abdullah Alkhawaldeh et al (15) pointed out that the rate of utilization and satisfaction were associated with many sociodemographic factors including employment, age, tobacco use, chronic illnesses and perceived general health status in a Jordanian study.

In the present study, although the satisfaction with university FPCs as reported by utilizers reached $88.6 \%$ and $80.3 \%$ in urban and rural areas respectively and the level of reutilization was also very high, the majority of respondents prefers to utilize other health care providers in the future mainly the private clinics and PHC centers of $\mathrm{MOH}$ in urban and rural areas respectively. This is because of lower cost of $\mathrm{MOH}$ services for rural people or the availability of more clinical services as elicited by urban utilizers. In an Indian study, more than two-thirds of the respondents listed private practitioners as their preferred choice of health care facility in case of illness followed by the primary health clinic. ${ }^{(16)}$ In Kuait, the majority of the patients reported that the time for communication between physician and patient was not enough and most of the surveyed patients said they would go to the emergency room of the hospital in future if needed instead of going to the primary care clinic. ${ }^{(17)}$
On one hand, the present study ranked treatment with courtesy and competency of the medical staff as the main reasons of utilizers' satisfaction with university FPCs in both rural and urban areas. On the other hand nonavailability of different specialties beside family medicine emerged as the main reason of dissatisfaction of both utilizers and non-utilizers of FPCs. In addition, short service time, and unavailability of ultrasound service ranked first among reasons of utilizers' dissatisfaction in urban areas while long waiting time and unavailability of free medications constituted the major areas of dissatisfaction in rural areas. In a study conducted in a primary care unit and included 547 patients, researchers in Florida found the major concerns driving patient dissatisfaction are rooted in wait time or poor telephone communication. ${ }^{(10)}$ In another study conducted by Khalid et $\mathrm{al}^{(18)}$ in Saudi Arabia, they reported that overall participants were quite satisfied with the services provided in primary health care centers. Patients who had longer waiting time particularly between registration and consultation showed higher rate of dissatisfaction with services provided.

Although a big team of qualified family doctors including residents and assistant lecturers are responsible for daily management of university FPCs, the reasons cited for the non-utilization of these centers in the present study included unqualified doctors. On the one hand this might explain the need for effective marketing plan to raise the awareness of people who had never thought to access and utilize these centers. On the other hand, the senior staffs like lecturers and professors of family medicine is requested to be more involved in daily service provision and supervision to meet people's expectation of the centers. 
In another study, though the awareness about primary health care clinics was quite high, only about half of the respondents who were aware had ever utilized the services of these health clinics. The reasons cited for non-utilization were nearly similar to those found in the present study and included inconvenient timing of the health clinic, long queues, unavailability of free drugs and deficient resources. ${ }^{(9)}$ Other international studies ranked absence of electricity and water, lack of basic work equipments and inappropriate staff composition as the main reasons for underutilization of primary health care services . (11-13) Although similarities of most of clients' needs, some needs still remaining different in various communities and requires continuous research and correction.

\section{Limitations}

The sample was selected among people attending the few meters nearby health offices owned by $\mathrm{MOH}$ as a probability sample representing the local community.

\section{Conclusion:}

The local community awareness utilization of Suez Canal University owned FPCs were very high in both rural and urban areas. Although the satisfaction with these FPCs as reported by utilizers reached $88.6 \%$ and $80.3 \%$ in urban and rural areas respectively and the level of reutilization was also very high, the majority of respondents prefers to access other health care providers in the future mainly the private clinics for urban utilizers and PHC centers of $\mathrm{MOH}$ for the rural utilizers. Nonavailability of different specialties beside family medicine emerged as the main reason of dissatisfaction of both utilizers and non-utilizers of FPCs. In addition, short service time, and unavailability of ultrasound service ranked first among reasons of utilizers' dis-satisfaction in urban areas while long waiting time and unavailability of free medications constituted the major areas of dissatisfaction in rural areas.

\section{References}

1) Kleczkowski B, Elling R, Smith D. Health system support for Primary Health Care. Geneva: World Health Organization; 1994. Available from:

www.ncbi.nlm.nih.gov/pmc/articles/P MC3437084/

2) EHSRP. Analysis and Reform Program, MOHP, Cairo, Egypt 2003. Available from: dhsprogram.com/pubs/pdf/SPA5/02cha pter02.pdf

3) World Bank. Egypt: 72 percent of Healthcare Costs are Out of Pocket. Available from http://www.worldbank.org/en/news/vid eo/2015/03/10/egypt-72-percent-ofhealthcare-costs-are-out-of-pocket

4) WHO Health Systems Profile. Egypt Regional Health Systems Observatory EMRO. available from: http://apps.who.int/medicinedocs/docu ments/s17293e/s17293e.pdf

5) World bank library. Available from: http://info.worldbank.org/etools/docs/li brary/48302/30801.pdf

6) Al Qatari G. \& Haran D. Determinants of users' satisfaction with primary health care settings and services in Saudi Arabia. International Journal for Quality in Health Care 1999; 11(6): 523-531.

7) Metwally D. Patients' Satisfaction with Primary Health Care in Egypt: Exploring the Gap between Rural and Urban Governorates. Journal of Social and Development Sciences 2014; 5 (4): 221-230.

8) Gadallah M, Zaki B, Rady M, Anwer W, Sallam I. Patient satisfaction with primary health care services in two districts of lower and 
upper Egypt. East Mediterr Health J. 2003; 9:422-30.

9) Binod Kumar Patro, Rakesh Kumar, Anil Goswami, Baridalyne Nongkynrih, Chandrakant S Pandav. Community Perception and Client Satisfaction about the Primary Health Care Services in an Urban Resettlement Colony of New Delhi. Indian J Community Med. 2008; Oct; 33(4): 250-254.

10) Keonahealth. Top 6 causes of patient dissatisfaction | 3 simple solutions. Available from: http://keonahealth.com/top-6causes-of-dissatisfaction-3-simplesolutions

11) Ortola P, Blanquer JJ, Rodriquez JJ, Rodrigo O, Villagrasa F, Climent JA. User satisfaction in primary care: Result of a home survey. Aten Primaria. 1993; 12:578-9.

12) Mendoza Aldana J, Piechulek $H$, alSabir A. Client satisfaction and quality of health care in rural Bangladesh. Bull World Health Organ. 2001; 79:512-7.

13) Baltussen RM, Yé Y, Haddad S, Sauerborn RS. Perceived quality of care of primary health care services in Burkina Faso. Health Policy Plan. 2002; 17:42-8.

14) Umunna, Zeluwa Ifeoma. Exploring the factors that contribute to poor utilization of primary health care services: a study of two primary health care clinics in Nasarawa State, Nigeria
2012. Available from: http://etd.uwc.ac.za/xmlui/bitstream/ha ndle/11394/4536/Umunna_MPH.

15) Abdullah Alkhawaldeh, Margo B. Holm, Jamal Qaddumi, Wasileh Petro, Madi Jaghbir, and Omar Al Omari. A Cross-Sectional Study to Examine Factors Associated with Primary Health Care Service Utilization among Older Adults in the Irbid Governorate of Jordan. Current Gerontology and Geriatrics Research 2014; 15: 13-2

16) Binod Kumar Patro, Rakesh Kumar, Anil Goswami, Baridalyne Nongkynrih, Chandrakant S Pandav. Community Perception and Client Satisfaction about the Primary Health Care Services in an Urban Resettlement Colony of New Delhi. Indian J Community Med. 2008 Oct; 33(4): 250-254.

17) Alquraini H, Alhashem AM, Shah MA, Chowdhury RI.Factors influencing nurses' attitudes towards the use of computerized health information systems in Kuwaiti hospitals. J Adv Nurs. 2007 Feb; 57(4):375-81.

18) Al-Nemer KA, Al-Homood IA, AlNemer AA, Al-Shaikh OM, AlSaidan MA, et al. A Multicenter Study of Factors Affecting Patient's Satisfaction Visiting Primary Health Care Clinics in Riyadh, Saudi Arabia. Fam Med Med Sci Res. 2015 4:169. 
Table (1) Sociodemographic data of the studied groups $(\mathrm{N}=900)$.

\begin{tabular}{|c|c|c|c|c|c|c|c|}
\hline & & \multicolumn{2}{|c|}{$\begin{array}{l}\text { Rural } \\
(\mathrm{N}=600)\end{array}$} & \multicolumn{2}{|c|}{$\begin{array}{l}\text { Urban } \\
(\mathrm{N}=300)\end{array}$} & \multirow{2}{*}{$\chi^{2}$} & \multirow{2}{*}{$\begin{array}{l}P \text { - } \\
\text { value }\end{array}$} \\
\hline & & $\mathbf{N}$ & $\%$ & $\mathbf{N}$ & $\%$ & & \\
\hline \multirow{2}{*}{ Gender } & Male & 105 & 17.5 & 127 & 42.3 & \multirow{2}{*}{64.464} & \multirow{2}{*}{$<0.001 *$} \\
\hline & Female & 495 & 82.5 & 173 & 57.7 & & \\
\hline \multirow{3}{*}{ Age } & $\leq \mathbf{3 0}$ & 308 & 51.3 & 129 & 40.3 & \multirow{2}{*}{5.560} & \multirow{2}{*}{$0.018 *$} \\
\hline & $>\mathbf{3 0}$ & 292 & 48.7 & 171 & 59.7 & & \\
\hline & Mean \pm SD & \multicolumn{2}{|c|}{$33.0 \pm 11.6$} & \multicolumn{2}{|c|}{$36.0 \pm 13.9$} & -- & -- \\
\hline \multirow{2}{*}{$\begin{array}{l}\text { Marital } \\
\text { status }\end{array}$} & Unmarried & 76 & 12.7 & 88 & 29.3 & \multirow{2}{*}{37.281} & \multirow{2}{*}{$<0.001 *$} \\
\hline & Married & 524 & 87.3 & 212 & 70.7 & & \\
\hline \multirow{2}{*}{$\begin{array}{l}\text { Educational } \\
\text { level }\end{array}$} & < Secondary & 321 & 53.5 & 74 & 24.7 & \multirow{2}{*}{67.517} & \multirow{2}{*}{$<0.001 *$} \\
\hline & $\geq$ Secondary & 279 & 46.5 & 226 & 75.3 & & \\
\hline \multirow{3}{*}{ Employment } & Working & 90 & 15 & 149 & 49.7 & \multirow{3}{*}{125.507} & \multirow{3}{*}{$<0.001 *$} \\
\hline & Not working & 497 & 82.8 & 143 & 47.7 & & \\
\hline & Retired & 13 & 2.2 & 8 & 2.6 & & \\
\hline
\end{tabular}

Table (2): Relation between respondents satisfaction and sociodemographic characteristics $(\mathrm{N}=706)$

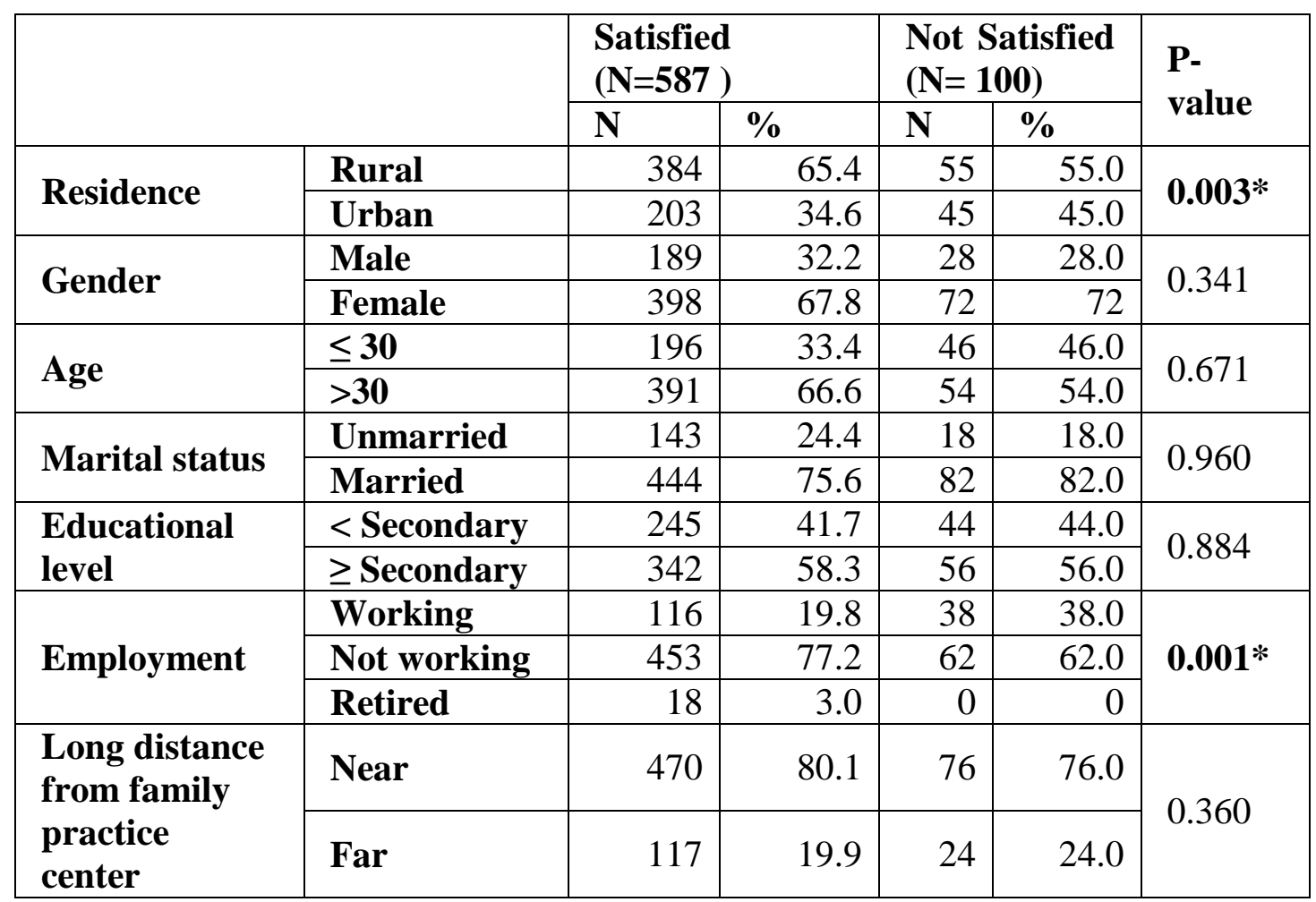




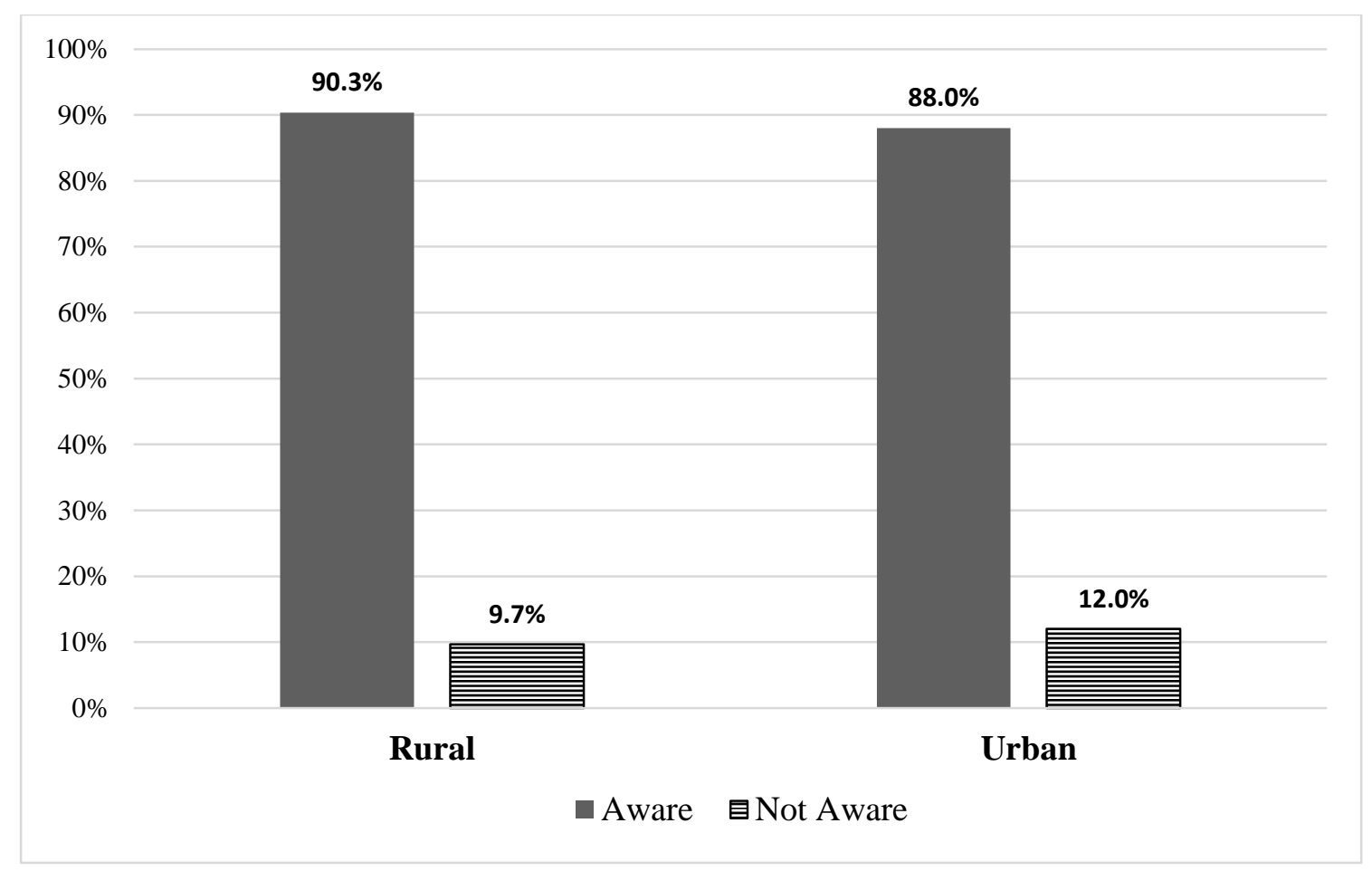

Figure 1: Respondents`Awareness of University FPCs (N=900). 


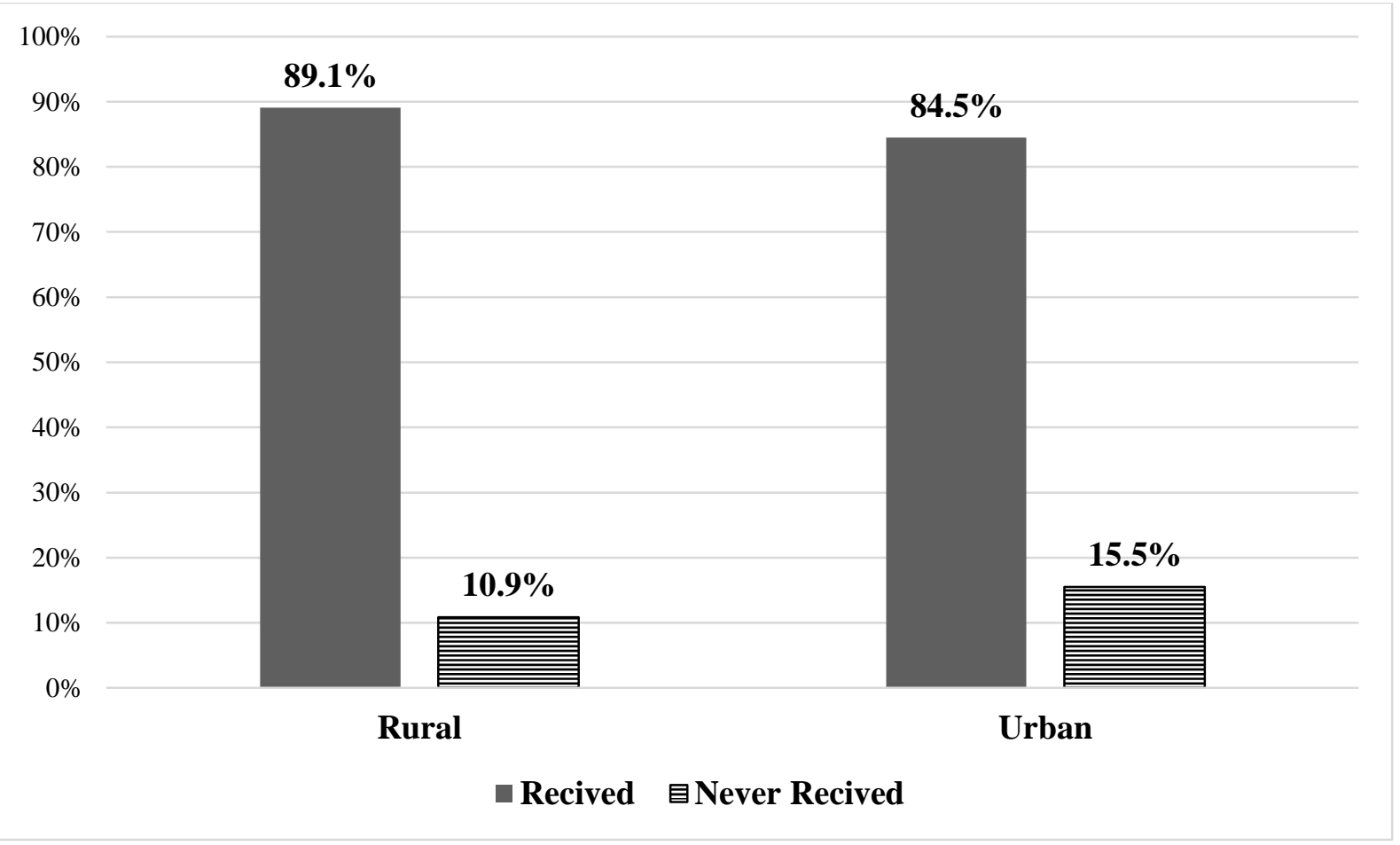

Figure 2: Utilization of Health Services Provided by the University FPCs among Aware Respondents (N=806)

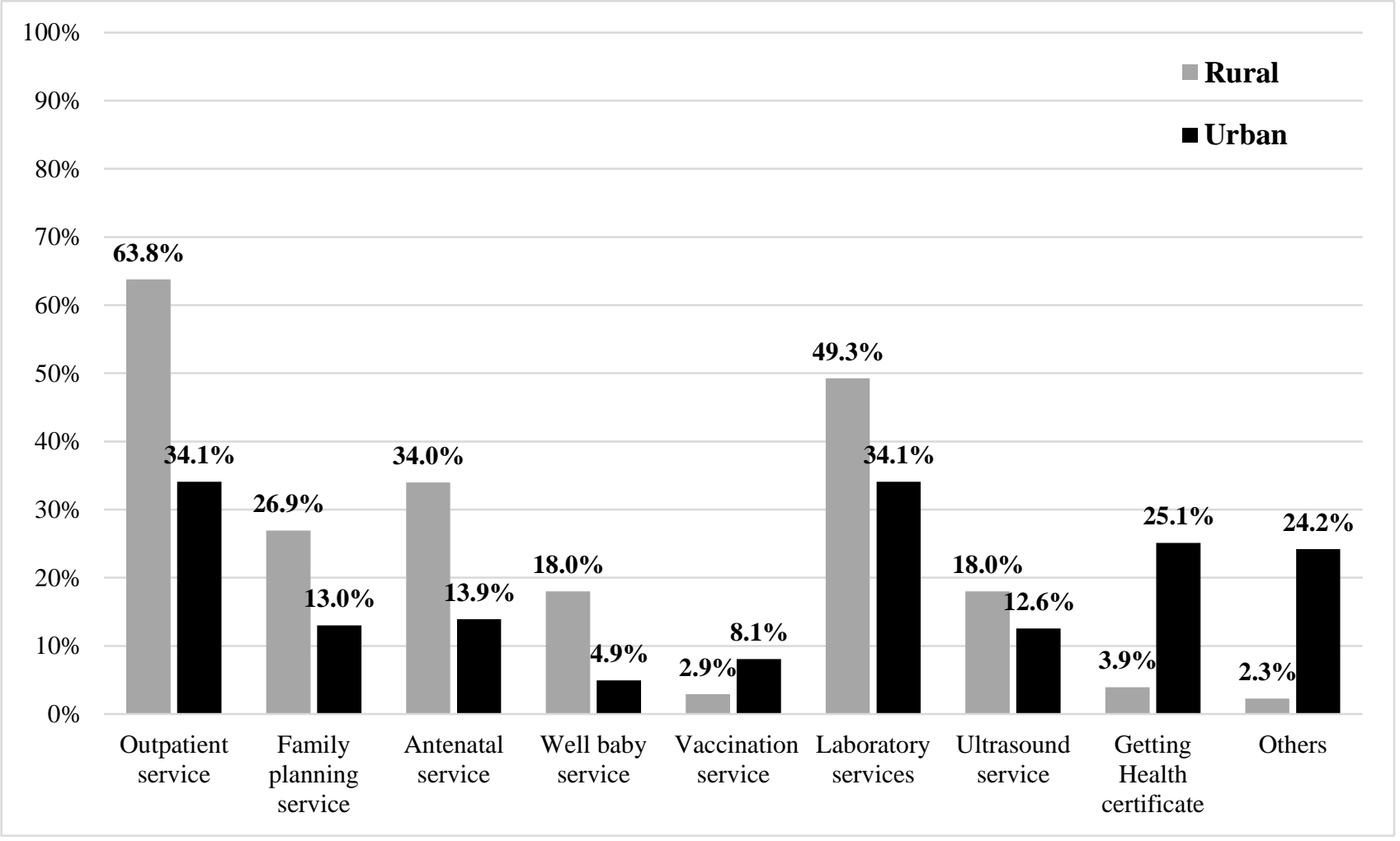

Figure 3: Utilizers` Frequency of the Utilization of Health Services Provided by the University FPCs (N=687). 


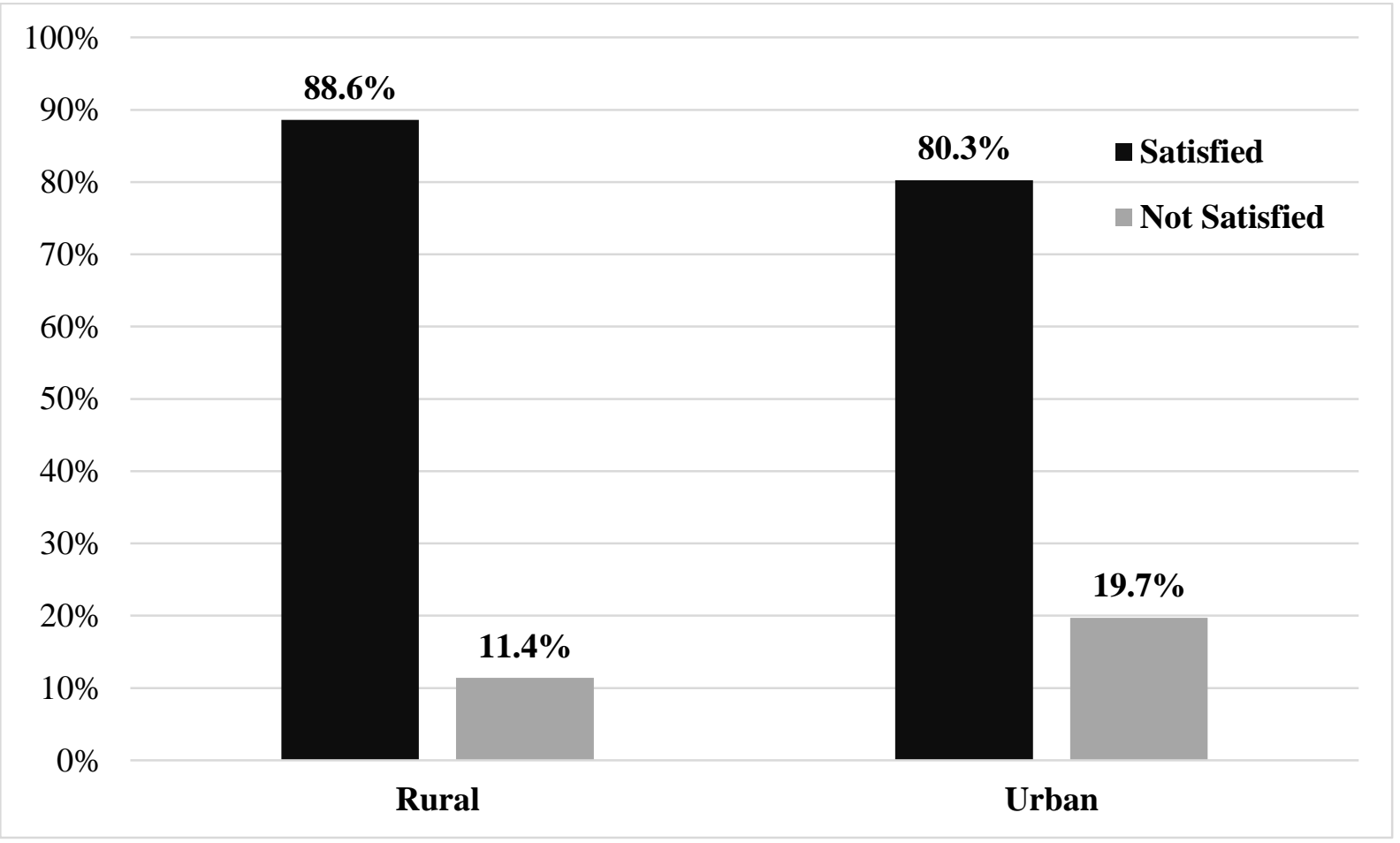

Figure 4: Utilizers' Satisfaction with Health Services Provided by the University FPCs $(\mathrm{N}=687)$. 


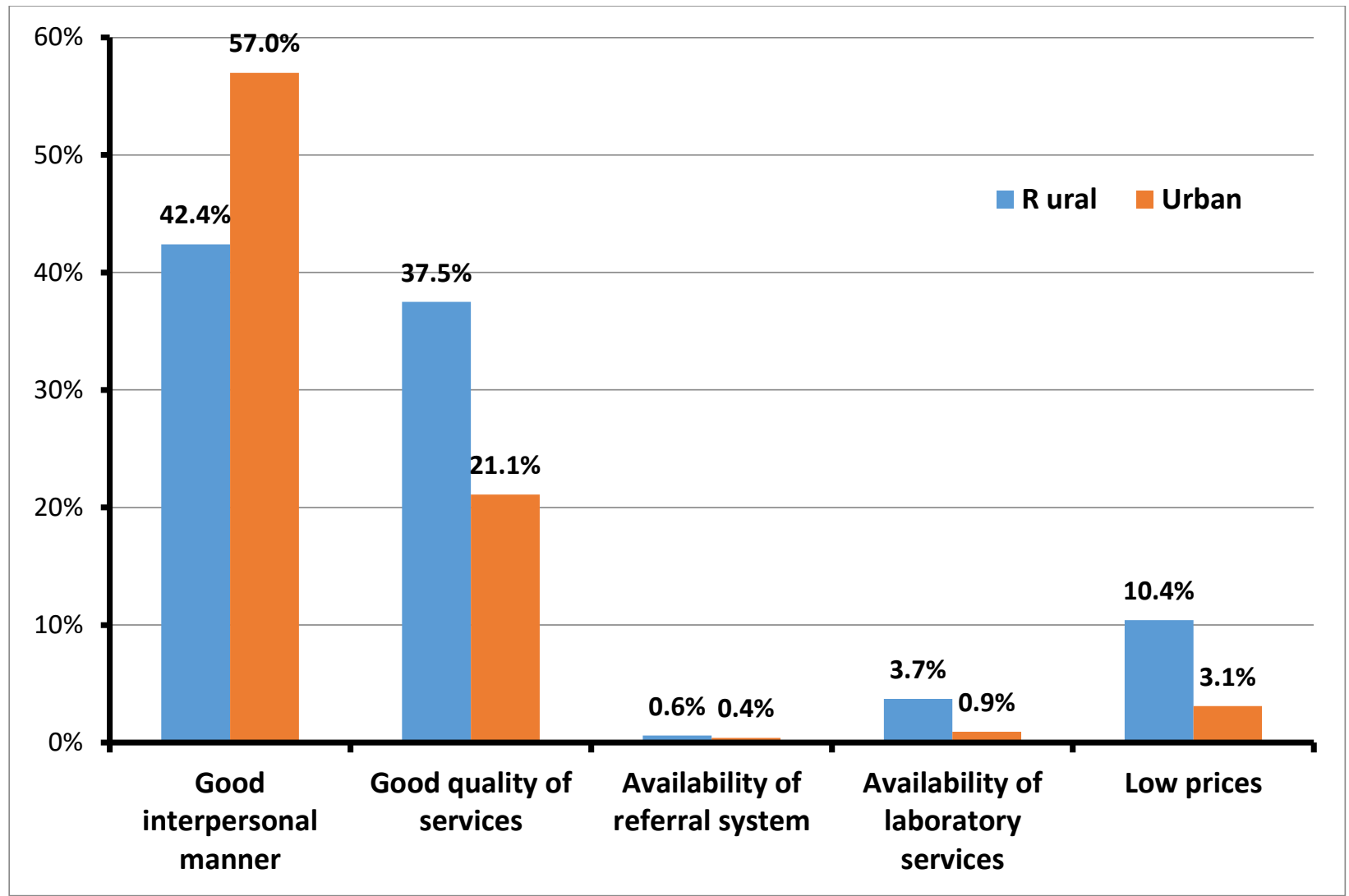

Fig 5: Reasons of Satisfaction with FPCs as Reported by Utilizers. 


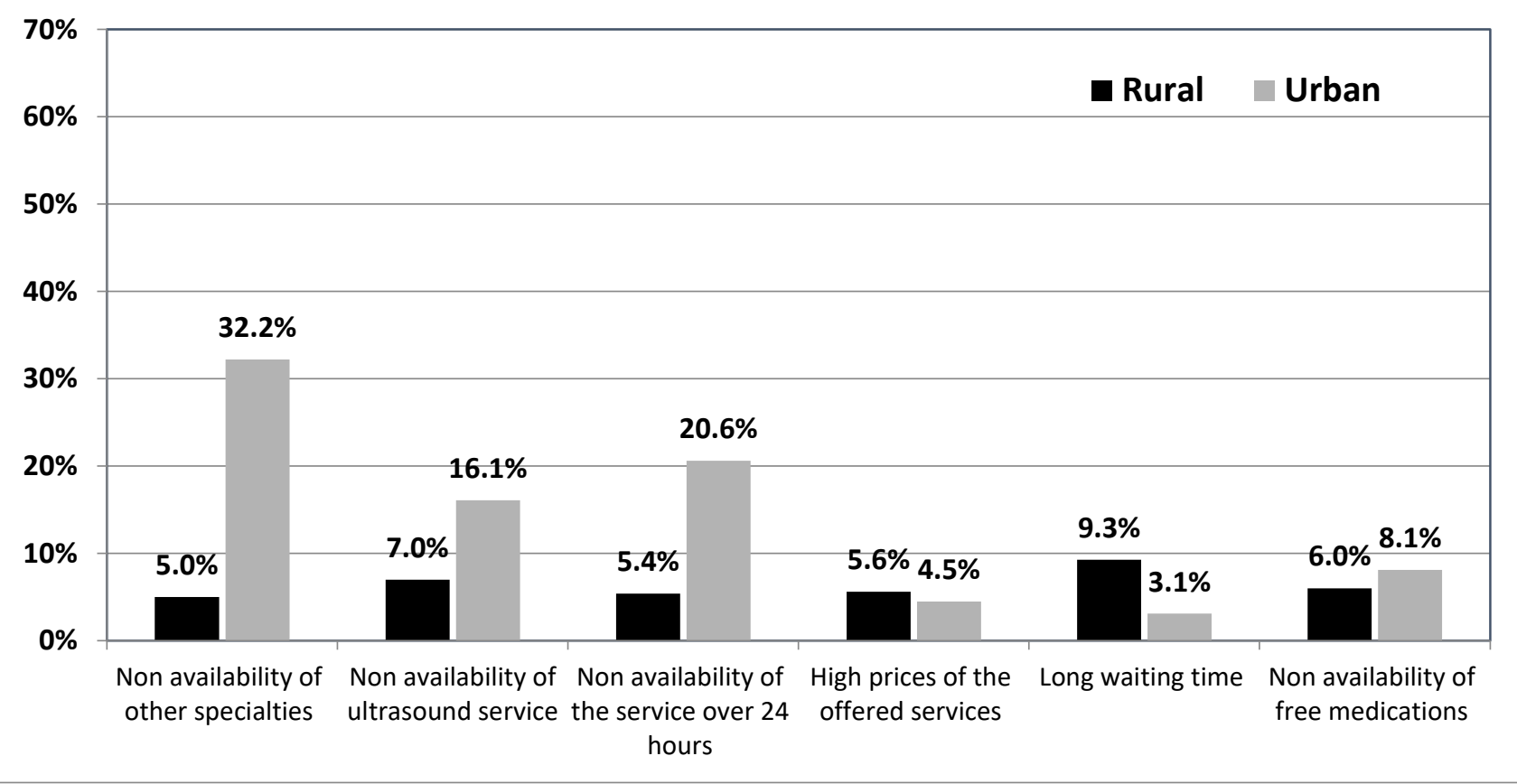

Figure 6: Reasons of Dissatisfaction with the University Family Practice Centers as Reported by the Dissatisfied Utilizers ( $n=100)$. 


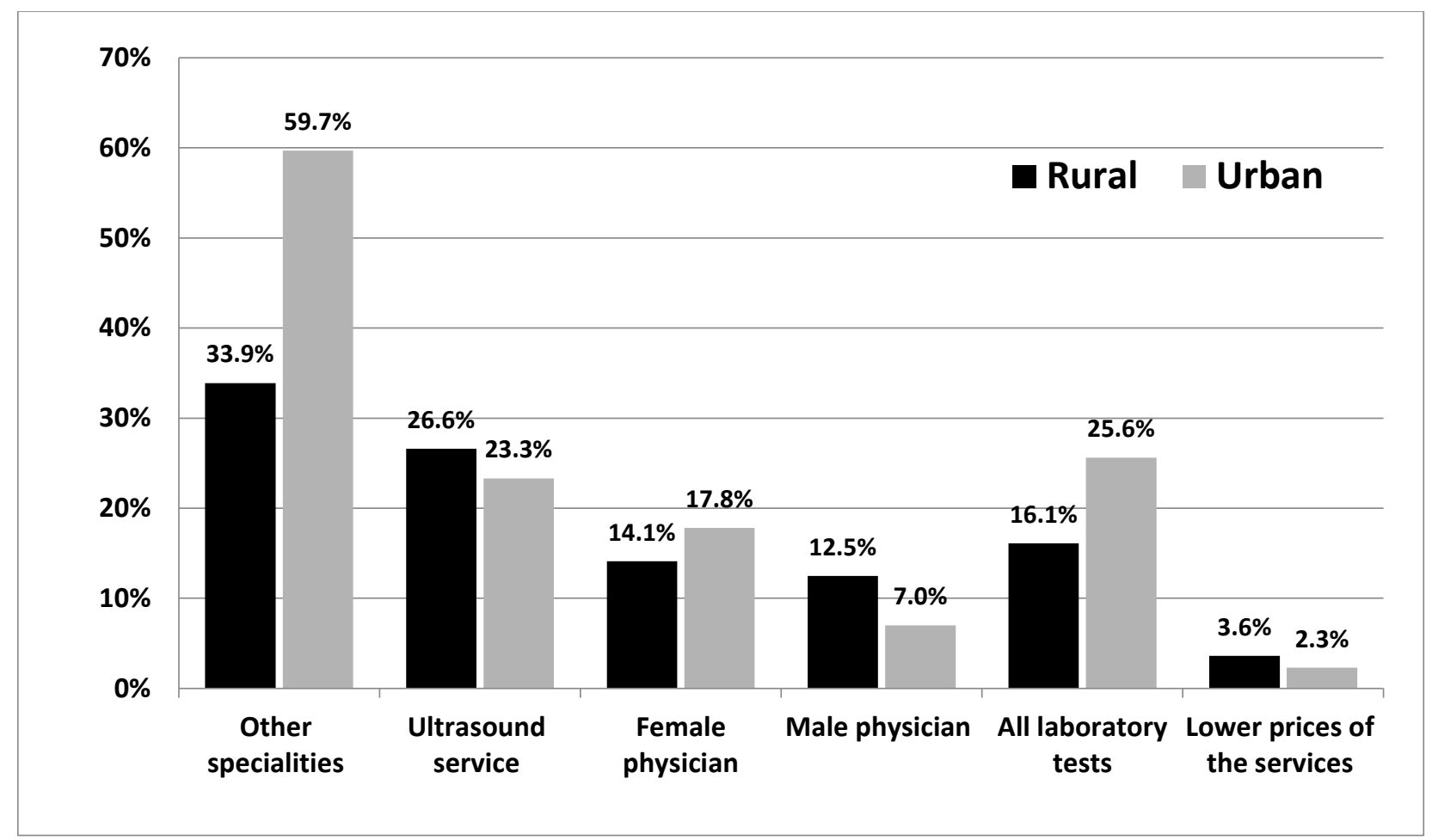

Figure 7: Needed Services in the University FPCs from the Point of View of Utilizers $(\mathrm{N}=687)$. 


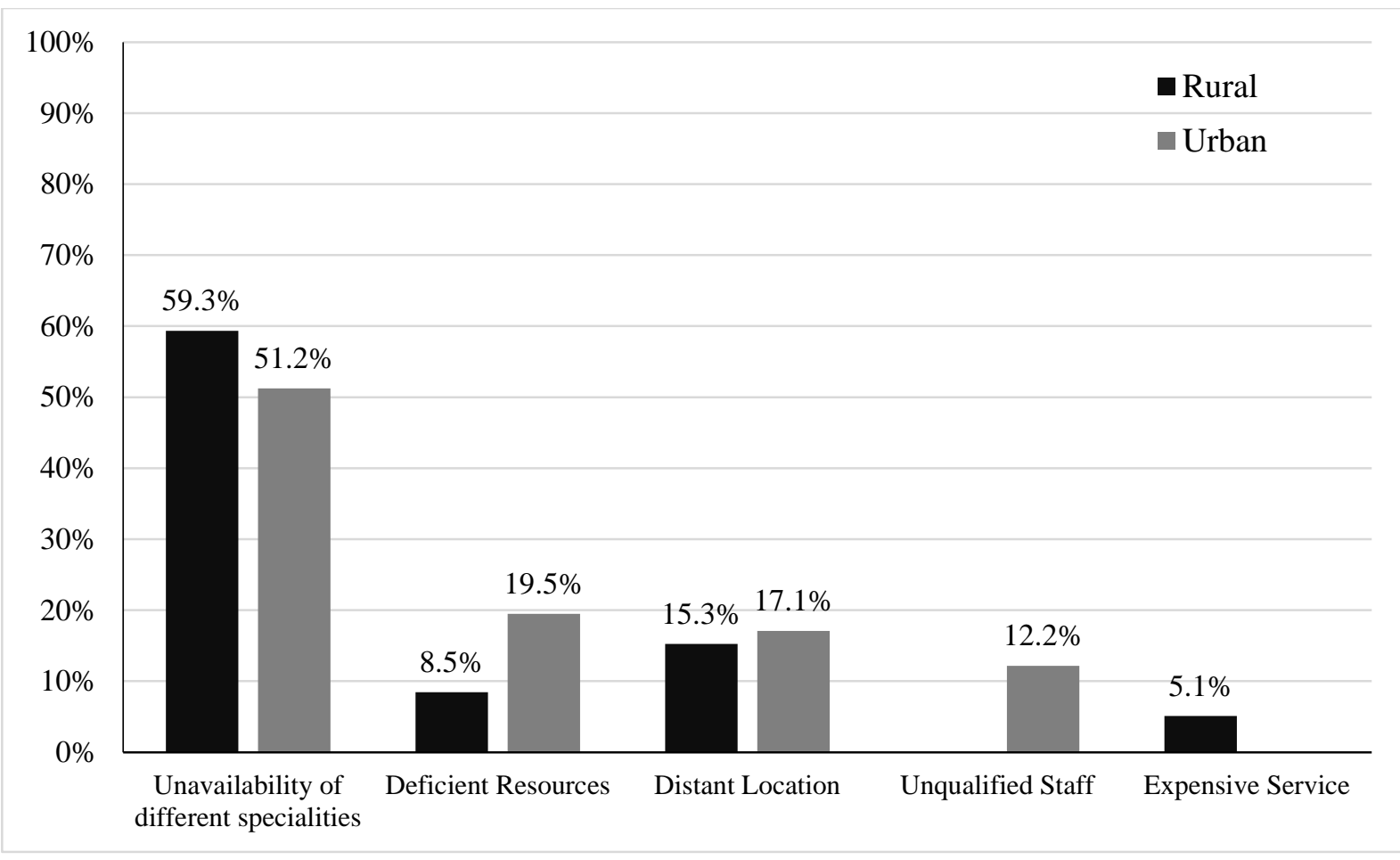

Figure 8: Reasons of Non-utilization of Health Services Provided by University FPC among Non-utilizers $(\mathrm{N}=119)$. 